Implicancias y Recusaciones: el caso del Tribunal Constitucional. Informe en derecho sobre la inhabilidad constitucional para conocer de un caso en el que se ha vertido opinión pública con anterioridad

\title{
IMPLICANCIAS Y RECUSACIONES: EL CASO DEL TRIBUNAL CONSTITUCIONAL. INFORME EN DERECHO SOBRE LA INHABILIDAD CONSTITUCIONAL PARA CONOCER DE UN CASO EN EL QUE SE HA VERTIDO OPINIÓN PÚBLICA CON ANTERIORIDAD*
}

Jorge Contesse Singh**

Pende ante el Tribunal Constitucional un requerimiento presentado por 32 diputados en contra del Decreto Supremo No 48/2007 del Ministerio de Salud, que autorizó las Normas Nacionales sobre Regulación de la Fecundidad, y que expresamente incluye, entre otros, el uso de anticoncepción de emergencia para mujeres de todas las edades y el dispositivo intrauterino. El caso, como se sabe, tiene un alto interés público. Ante la justicia ordinaria, de hecho, se han presentado diversas acciones legales cuyo objeto ha sido impugnar la juridicidad de los actos administrativos que desde la década pasada han regulado la venta y comercialización de los medicamentos cuyo elemento activo es el levornogestrel en $0,75 \mathrm{mg}$.

El presente informe se hace cargo de un asunto particular que se debate ante el Tribunal Constitucional, a saber, la petición para que dos señores Ministros se impliquen y no participen de la deliberación del caso. Argumentaré que existen razones constitucionales fuertes para sostener dicha posición y que, revisando casos comparados y la propia práctica constitucional del Tribunal nacional, los Ministros debieran voluntariamente inhabilitarse para conocer este caso.

* Informe en derecho presentado al Tribunal Constitucional el día 19 de octubre de 2007.

** Licenciado en Ciencias Jurídicas y Sociales (Univ. Diego Portales); LL.M. y candidato a Doctor en Derecho (Yale University). Profesor de Derecho, Universidad Diego Portales (Santiago) y Crowley Fellow in International Human Rights, Leitner Center for International Law and Justice, Fordham Law School (New York). E-mail: contesse@law.fordham.edu 
El plan es el siguiente. En primer lugar, revisaré el principio constitucional del debido proceso que debe gobernar la labor del Tribunal cuya misión no es otra que custodiar el orden constitucional. Para efectos de la cuestión aquí discutida, estos principios pueden subsumirse en la exigencia constitucional de la imparcialidad del juzgador (I). En seguida, ofreceré algunos ejemplos del derecho comparado donde se ha debatido la misma cuestión que analizo en estas páginas. Veremos que la tendencia en países con una sólida práctica constitucional es establecer estándares elevados de imparcialidad del tribunal (II). Posteriormente, retomaré el análisis de nuestro país dando cuenta de cuatro casos en los que precisamente Ministros de este Tribunal Constitucional han interpretado el deber de inhabilitarse en causas donde su imparcialidad pudiera cuestionarse, de conformidad con lo dispuesto por la ley orgánica constitucional del Tribunal Constitucional. La revisión de estos casos indica que el criterio dentro del actual Tribunal es compartido y que no hay motivos para que en este caso en particular se aparte de él (III). Luego, examinaré de qué manera debe encararse el equilibrio entre la imparcialidad de los miembros del Tribunal Constitucional y sus actuaciones previas en calidad de expertos: sostendré que el modo de determinar cuándo y cómo se configura el deber de inhabilitarse está vinculado con el análisis de las condiciones particulares del caso que reclame la intervención del Tribunal, siempre procurando satisfacer en la mayor medida posible el principio de imparcialidad del juzgador (IV). Finalmente, concluiré que la tramitación pendiente ante el Congreso Nacional del proyecto de ley orgánica del Tribunal Constitucional no puede aducirse como razón para no abordar esta importante cuestión. Se trata del órgano en el cual los ciudadanos y demás poderes del Estado han depositado su confianza constitucional, por lo cual, del mismo modo, la respuesta del Tribunal debe estar a la altura de dichas expectativas (V).

\section{Imparcialidad del juzgador: principio rector de la labor del Tribunal Constitucional}

El Tribunal Constitucional (en adelante, “TC”), al igual que cualquier tribunal ordinario, está sometido a diversos principios y normas del debido proceso. Se trata de un órgano del Estado cuya misión no es sino dar seguridad que la Constitución siempre será la norma superior, dando así plena vigencia al principio de supremacía constitucional, contemplado en el capítulo I de la Carta Fundamental. En tanto sus miembros ejercen jurisdicción, les son aplicables las normas que regulan la labor de cualquier juez de la República. Pero, como argumentaré más adelante, también el TC es un órgano especial; no es idéntico a un juez que forma parte del Poder Judicial, si bien comparte con él la labor de "dictar el derecho". El TC, en efecto, debe lidiar con disputas constitucionales, que hacen más fina la separación entre derecho y política. Por lo mismo, su labor es especialmente delicada.

Ante el Tribunal Constitucional los ciudadanos y los poderes del Estado allegan razones a favor y en contra de posiciones jurídicas que determinarán el alcance de la ley, de actos administrativos y, obviamente, de la propia Constitución. En consecuencia, las decisiones del TC deben siempre estar revestidas de toda legitimidad; de lo contrario, la confianza en el trazado institucional se lesiona, dando espacio a sospechas en el Estado de Derecho y, con ello, 
Implicancias y Recusaciones: el caso del Tribunal Constitucional. Informe en derecho sobre la inhabilidad constitucional para conocer de un caso en el que se ha vertido opinión pública con anterioridad

abriendo la puerta a la arbitrariedad.

Tras la reforma constitucional de 2005, que otorgó competencia exclusiva para conocer de los requerimientos de inaplicabilidad por inconstitucionalidad al Tribunal Constitucional, la mirada sobre lo que este órgano del Estado haga (y deje de hacer) se ha hecho especialmente importante. El TC, consecuentemente, está en el centro de la discusión constitucional y por lo mismo su labor parece hoy más importante y sensible que nunca.

La Constitución dispone, en su artículo 19 numeral 3, los principios sobre el debido proceso que han de animar la labor de todo juzgador. En particular, el inciso $5^{\circ}$ de dicho precepto dispone que "toda sentencia de un órgano que ejerza jurisdicción debe fundarse en un proceso previo legalmente tramitado. Corresponderá al legislador establecer siempre las garantías de un procedimiento y una investigación racionales y justos". La cláusula constitucional contempla dos situaciones: de una parte, una regla general que obliga a todo juzgador a respetar las normas del debido proceso al momento de dictar sentencia y, de otra parte, un principio de reserva legal para el establecimiento de dichas normas sobre el debido proceso.

El legislador ha cumplido con este mandato constitucional en una serie de materias. ${ }^{1}$ Así, la regulación común -que se encuentra en el Código Orgánico de Tribunales, así como en el Código de Procedimiento Civil y el Código Procesal Penal, entre otros cuerpos normativosestablecen la manera como el proceso puede legítimamente disponer sobre situaciones jurídicas particulares. Respecto del trabajo del Tribunal Constitucional, la ley también se ha hecho cargo de establecer los procedimientos que legitiman la adopción de decisiones que después, independientemente del resultado de fondo, deben ser consideradas como justas precisamente por haber sido adoptadas en el marco de un "justo y racional procedimiento".?

Uno de los principios fundamentales sobre la materia es, como se sabe, el de imparcialidad del tribunal, según el cual las sentencias pronunciadas por los órganos que ejercen jurisdicción solo son legítimas cuando se dictan en el marco de un procedimiento que no deja dudas acerca de la posición desprejuiciada del tribunal. Se trata, sin más, de la imagen de Iustitia, representación romana de la justicia, que junto con sostener la balanza donde pesa los argumentos de cada litigante y la espada con que ejerce su capacidad de coerción, lleva sus ojos vendados para asegurar que su interés es resolver el asunto sin más juicio que lo que las partes, en ese procedimiento, avancen. Todo lo demás, todas las apreciaciones que se pueda haber formado

En otras, sin embargo, la omisión legislativa es grave, siendo quizá la falta de regulación legislativa del procedimiento sobre tramitación de la acción de protección el ejemplo más claro. Como se sabe, dicho procedimiento ha sido establecido, en ausencia de ley, por la Corte Suprema, a través de un Auto Acordado. Ley No 17.997, orgánica constitucional del Tribunal Constitucional, publicada en el Diario Oficial de 19 de mayo de 1981. 
de otra manera, se entiende que contaminan la delicada labor de quien ha de dictar justicia. De allí que el asunto que en estas páginas examino -la afectación a la imparcialidad del tribunalsea de la más alta importancia. La propia jurisprudencia del TC es clara al respecto. En la sentencia Rol 47/1987, el Tribunal señaló estar de acuerdo en "que todo juzgamiento debe emanar de un órgano objetivamente independiente y subjetivamente imparcial, elementos esenciales del debido proceso que consagra toda la doctrina procesal contemporánea". Es más, a juicio de este Tribunal, la independencia e imparcialidad del juez no sólo son componentes de todo proceso justo y racional, sino, además, son elementos consustanciales al concepto mismo de tal. ${ }^{3}$

La idea según la cual la imparcialidad del tribunal es un componente esencial del debido proceso implica que, de no respetarse dicho principio, la lesión a las normas sobre el justo y racional procedimiento impactará en la legitimidad de la decisión final que adopte dicho tribunal. Si no hay imparcialidad o, lo que para estos efectos es lo mismo, si existe duda acerca de la imparcialidad del juzgador, todo lo que él haga estará teñido de un manto de ilegitimidad que la justicia constitucional debe resistir. Por ello el Tribunal Constitucional español ha reiterado recientemente que "[1]a garantía de un Tribunal independiente y alejado de los intereses de las partes en litigio constituye una garantía procesal que condiciona la existencia misma de la función jurisdiccional". 4

La legislación que regula la labor del TC se hace eco de estas nociones, disponiendo, en su artículo 19, inciso $1^{\circ}$, que es motivo de implicancia de un Ministro "el hecho de haber emitido opinión con publicidad o dictamen sobre el asunto concreto actualmente sometido a conocimiento del Tribunal". En el caso que convoca este informe, dos Ministros del Tribunal Constitucional se encuentran en la hipótesis contemplada por la ley orgánica del TC.

En efecto, con ocasión de uno de los juicios que se ha substanciado ante la justicia ordinaria impugnando la autorización otorgada por la Administración del Estado para la comercialización y venta de los medicamentos con el componente activo levonorgestrel en $0,75 \mathrm{mg}$., dos miembros del TC participaron, en calidad de académicos expertos en materias constitucionales, en un informe en derecho que directamente argumentaba a favor de una de las partes de dicho litigio (de hecho, el escrito fue acompañado por la parte demandante en juicio seguido ante un juzgado de letras). En él, los Ministros expresamente se pronunciaron sobre la constitucionalidad -a su juicio, sobre la inconstitucionalidad - del medicamento en cuestión, quedando, como argumentaré en estas páginas, impedidos de conocer en el caso que se sigue actualmente ante el TC.

Tribunal Constitucional, sentencia recaída en la causa Rol 46/1987, de 21 de diciembre de 1987, considerando $10^{\circ}$ (el destacado es mío).

Tribunal Constitucional de España, STC 26/2007, de 5 de febrero de 2007, parte II.3. 
Implicancias y Recusaciones: el caso del Tribunal Constitucional. Informe en derecho sobre la inhabilidad constitucional para conocer de un caso en el que se ha vertido opinión pública con anterioridad

Y es que si la imparcialidad del tribunal, como norma reguladora del debido proceso, importa que el juzgador se acerque al caso que convoca su intervención sin una opinión formada sobre los hechos y el derecho -pues para ello, precisamente, existe el procedimiento en el que las partes litigan-, dicho principio es lesionado severamente cuando, como ocurre en este caso, uno o más Ministros han estudiado profundamente y se han formado una convicción jurídica acerca de la materia debatida. Para decirlo gráficamente, la justicia no tiene los ojos vendados al momento de pesar los argumentos de las partes; a través de esa actuación ella ha observado lo que hay en la balanza y, más aún, ha dicho cuál es su opinión al respecto. El principio de imparcialidad del tribunal, que sirve de estándar para medir las actuaciones de los Ministros implicados, no puede aceptar que, habiendo emitido juicio en un proceso (de lo que se sigue que el dictamen no tiene el carácter de privado), los Ministros escuchen los alegatos de las partes como si no conocieran los argumentos ex ante.

¿Quiere decir lo anterior que los Ministros quedan inhabilitados para conocer de cualquier caso en el que hayan pronunciado algún tipo de opinión? No necesariamente. La norma sobre la implicancia es abierta, en el sentido que requiere interpretación por parte de los operadores del derecho; en particular, por parte del propio Tribunal Constitucional. En la clasificación de las normas, se trata de un principio, de un mandato de optimización, más que de una regla jurídica. ${ }^{5}$ Lo que esta norma busca realizar es, obviamente, la imparcialidad del tribunal, la que puede ser más o menos cumplida según cuáles sean las circunstancias particulares de la situación. En este caso, en que los Ministros intervinieron -como parte de un grupo de académicosdirectamente en un caso de alto interés público, el cual la ciudadanía sigue muy de cerca, es evidente que la presunción de imparcialidad que ha de acompañar la labor del TC se ve afectada. Dicho de otra manera, aun cuando los Ministros, cuya integridad profesional no se cuestiona por estar implicados, hicieran el mejor esfuerzo por volver a vendar sus ojos, lo cierto es que razonable y legítimamente cualquier persona puede dudar que logren hacer tal cosa.

Como mostraré a continuación, ésta es precisamente la regla que otras jurisdicciones han adoptado: basta la sospecha, la duda, la presunción que una persona normal pueda abrigar sobre la imparcialidad con la que un juzgador se acerca a un caso determinado para que éste quede legítimamente cuestionado en su intervención y, en consecuencia, implicado o bajo causal de recusación. Más aún, el proyecto de ley orgánica sobre el Tribunal Constitucional, actualmente en discusión en el Congreso Nacional, al extender las causales de implicancia y recusación a los abogados integrantes del TC, recoge expresamente la tendencia del derecho comparado al establecer que "será causal de recusación la existencia de relaciones laborales, comerciales o societarias con el abogado o procurador de algunas de las partes que requieran de inaplicabilidad, o que ejerzan la acción pública en los casos en que la Constitución o la ley lo autoricen, que

Sobre la distinción entre reglas y principios jurídicos, véase Robert Alexy, Teoría de los Derechos Fundamentales (trad. de Ernesto Garzón Valdés), Madrid: Centro de Estudios Constitucionales, 1993. 
Jorge Contesse Singh

permitan presumir que su imparcialidad se encuentra comprometida". ${ }^{6}$

Así, entonces, y como diré a continuación, los Ministros cuestionados debieran voluntariamente dar un paso al lado si desean cuidar la integridad del órgano llamado nada menos que a custodiar el orden constitucional. De no hacerlo, la señal que se enviaría a los demás poderes del Estado y a la ciudadanía es que el Tribunal Constitucional no repele la imagen de la justicia con sus ojos abiertos y la balanza cargada hacia un lado ex ante.

\section{Derecho comparado}

La situación motivada por la intervención en calidad de académicos de dos Ministros en un juicio en el que se debatía la misma cuestión que pende actualmente en el Tribunal Constitucional ha sido abordada en diversas jurisdicciones comparadas. Las soluciones que se encuentran, si bien difieren -como es común que acontezca en materias constitucionales-, tienen en común el avanzar lo que podríamos denominar una "máxima de certeza de la imparcialidad del tribunal". Según ella, la habilidad para conocer de un caso por parte de un miembro de la justicia constitucional queda legítimamente cuestionada toda vez que existan presunciones fundadas que hagan al menos dudar de la imparcialidad. En otras palabras, lo que los sistemas constitucionales protegen con celo no es solo la imparcialidad, sino la apariencia de imparcialidad. A continuación reviso el caso de España y el de los Estados Unidos.

\section{II.1. España}

En febrero de 2007, el Tribunal Constitucional español -órgano con más de veinte años de jurisprudencia - resolvió un caso muy similar al que convoca estas páginas. Se trata de la recusación presentada por un partido político en contra del magistrado del TC español, Pablo Pérez Tremps, en el marco de una acción de inconstitucionalidad referida al Estatuto de Cataluña. El juez Pérez Tremps, catedrático en derecho constitucional de la Universidad Carlos III de Madrid, había elaborado un estudio (antes de ser nombrado magistrado) relacionado, aunque indirectamente, con cuestiones constitucionales que el TC debía ahora resolver. En un fallo dividido, el pleno del TC español hizo lugar a la recusación presentada en contra del magistrado por estimar que, al haber emitido opinión técnica previamente, la imparcialidad del tribunal quedaba en entredicho. ${ }^{7}$

La decisión no estuvo exenta de debate. Para algunos, con esta doctrina el TC se ataba de manos pues muchos de sus miembros han emitido opiniones jurídicas sobre materias que eventualmente pueden llegar hasta el Tribunal y serían ahora fácilmente recusados por la parte

Boletín 4059-07, que modifica la Ley 17.997.

Tribunal Constitucional de España, STC 26/2007, de 5 de febrero de 2007. 
Implicancias y Recusaciones: el caso del Tribunal Constitucional. Informe en derecho sobre la inhabilidad constitucional para conocer de un caso en el que se ha vertido opinión pública con anterioridad

cuyos intereses no coinciden con la opinión técnica emitida anteriormente por el juez. Además, se dijo, los magistrados del Tribunal Constitucional son nombrados, entre otras cosas, precisamente porque tienen un conocimiento y experticia que suele reflejarse en opiniones escritas sobre temas particulares. Con esta doctrina, potenciales miembros de un tribunal constitucional quedarían inhibidos de pronunciarse públicamente sobre materias de su ámbito de capacidades, generándose un incentivo perverso para la práctica constitucional de los países.

Los argumentos son razonables -aunque no derrotan la posición que aquí defiendo- y sobre ellos me haré cargo hacia el final de este escrito. Por el momento, valga revisar las consideraciones que motivaron la decisión del TC español y que, como diré, confirman la tesis según la cual este tipo de situaciones han de resolverse en atención a las circunstancias fácticas y jurídicas de cada caso, siempre apuntando a realizar en todo lo posible el principio de imparcialidad del tribunal.

El magistrado español recusado había emitido un dictamen remunerado sobre las relaciones exteriores de Cataluña -en especial, con la Unión Europea-, el que fue encargado por el Instituto de Estudios Autonómicos de la Generalitat de Cataluña para asesorar al Parlamento catalán en la elaboración del nuevo "Estatut", y que posteriormente sirvió de base para la reforma a dicho cuerpo normativo. De acuerdo con el voto de mayoría del TC, el magistrado incurrió en la causal de recusación que lo inhabilita por "haber ocupado un cargo público, desempeñado empleo o ejercido profesión con ocasión de los cuales haya participado directa o indirectamente en el asunto objeto del pleito o causa o en otro relacionado con el mismo". ${ }^{8}$

Aun cuando el caso se asemeja al que actualmente debe decidir el Tribunal Constitucional chileno, su par español decidió, en aras de la imparcialidad del juzgador, aceptar la recusación en contra de uno de sus miembros por razones que podrían estimarse aun más débiles que las existentes en el presente caso. En primer lugar, el juez Pérez Tremps elaboró un informe que posteriormente fue utilizado en la tramitación parlamentaria. Los Ministros señores Bertelsen y Navarro, en cambio, participaron de un informe cuyo destino no era otro que servir de apoyo a la pretensión de uno de los litigantes en un juicio ya existente. En segundo lugar, el Ministerio Fiscal de España se opuso a la recusación del magistrado aduciendo que el estudio "no [constituía] un análisis técnico jurídico para verificar la adecuación [de la norma] a la Constitución", ${ }^{9}$ por lo que cabe concluir, a contrario sensu, que de ser un estudio de ese tipo sí habría lugar a la recusación. En esta línea de reflexión, es inevitable concluir que los Ministros sí emitieron un análisis técnico-jurídico sobre la (in)adecuación de los medicamentos levonorgestrel en 0,75 mg. a la Carta Fundamental chilena: el informe en derecho por ellos suscrito, acompañado por la parte demandante en la causa Rol N ${ }^{\circ}$ C-5839-2002, el día 18 de diciembre de 2003, concluye expresamente que

Artículo 219 numeral 13 de la Ley Orgánica del Poder Judicial de España.

El País, "El Constitucional acepta la recusación de Pérez Tremps planteada por el PP”, 5 de febrero de 2007. 
Jorge Contesse Singh

... la decisión del Instituto de Salud Pública por la que autorizó por segunda vez la venta y distribución de la droga Levonorgestrel 0,75 [...] constituye un atentado a la Constitución ...". ${ }^{10}$

No hay duda, entonces, que los dos Ministros mencionados emitieron su juicio (constitucional) sobre el objeto del requerimiento que actualmente se tramita ante el Tribunal Constitucional, explicitando su parecer sobre la juridicidad de un acto de la Administración del Estado que hoy, si bien está contenido en un instrumento diverso -un Decreto Supremo del Ministerio de Salud, y no del Instituto de Salud Pública-, produce los mismos efectos de fondo.

El Tribunal Constitucional español, consciente de la relevancia de sus actuaciones, determinó inhabilitar a uno de sus pares de manera de custodiar fielmente la integridad del sistema constitucional por un estudio que tenía menos relación que la que tiene el informe aquí referido con lo que se discute en el caso actualmente sometido ante el TC. A fortiori, los miembros del Tribunal Constitucional chileno tienen mayores razones para inhabilitarse de conocer el requerimiento en contra del Decreto Supremo 48/2007 del Ministerio de Salud.

\section{II.2. Estados Unidos}

Como es sabido, la revisión judicial de las leyes encuentra su fundamento último en la famosa decisión de la Corte Suprema de los Estados Unidos, Marbury v. Madison, de 1803. ${ }^{11}$ Fue con esta sentencia que el juez Marshall inauguró acaso la facultad más importante que la Corte en ese país tiene: revisar la conformidad de las leyes adoptadas por el Congreso a la Constitución Federal. La existencia de cortes constitucionales separadas de los órganos del Poder Judicial, propia de la tradición europeo-continental, arranca con el Tribunal austriaco y los escritos del jurista Hans Kelsen, en la segunda década del siglo XX. Si bien el modelo adoptado por nuestra Constitución se asemeja más al europeo que al estadounidense, la influencia que este último ha tenido sobre las jurisdicciones constitucionales en el mundo es innegable. Nuestro sistema constitucional, por ejemplo, sigue de cerca al sistema de los Estados Unidos de nombramiento de los miembros del Tribunal Constitucional. ${ }^{12}$

En la jurisdicción constitucional de los Estados Unidos, el primer caso sobre recusación

AA.VV., Informe en Derecho: El derecho a la vida y su titularidad. Algunas consideraciones a propósito de la comercialización de la droga levonorgestrel 0.75 , s/f, par. 25.

5 U.S. (1 Cranch) 137 (1803).

Hay quizá una importante diferencia, relacionada con la falta en nuestro país de una discusión vigorosa al momento de seleccionar a quienes tendrán a su cargo la delicada misión de custodiar a la Constitución: en los 
Implicancias y Recusaciones: el caso del Tribunal Constitucional. Informe en derecho sobre la inhabilidad constitucional para conocer de un caso en el que se ha vertido opinión pública con anterioridad

data de 1927. ${ }^{13}$ En él, la Corte estableció como violación a la cláusula sobre debido proceso legal la mera existencia de "una posible tentación para que [...] el juez promedio eventualmente sea conducido a no mantener un balance apropiado, claro y certero". ${ }^{14}$ Como se aprecia, la regla es estricta en el sentido de guardar no solo la certeza de la imparcialidad, sino su apariencia. Y es que la Corte entiende que, siendo el derecho un sistema formal que decide sobre la vida, propiedad y libertad de las personas, la garantía de seguridad jurídica no puede respetarse si no se es extremadamente cuidadoso en la manera - la forma jurídica- como la Corte desarrolla su labor y como la ciudadanía recoge dicho trabajo. En efecto, la Corte, reiterando su jurisprudencia en la materia, sostuvo que "para desempeñar sus funciones de la mejor manera posible, 'la justicia debe satisfacer la apariencia de justicia". ${ }^{15}$ Como ya hemos dicho en estas páginas, no es solo el fondo, sino también la forma como se administra justicia (en este caso, constitucional) la que debe resguardarse al momento de decidir sobre una implicancia o recusación.

En los Estados Unidos, además, existe regulación expresa sobre las recusaciones en contra de los jueces. De acuerdo con lo establecido en el United States Code, "todo juez de los Estados Unidos deberá inhabilitarse en cualesquier procedimiento en el que su imparcialidad pueda razonablemente ser cuestionada". ${ }^{16} \mathrm{Al}$ igual que en el caso español, la regulación en la materia es extremadamente celosa cuando se trata de asegurar a las partes que quien habrá de decidir la controversia no lo hará en base a juicios previos, sino únicamente en atención a lo que el merito de ése proceso arroje. Por algo se trata de jurisdicciones con una sólida tradición constitucional.

Durante los últimos años ha existido cierta controversia con la manera como se ha de aplicar la regla de recusación e implicancia. En particular, uno de los jueces de la Suprema Corte, Antonin Scalia, ha sido objeto de críticas por su negativa a recusarse en casos en los que razonablemente su imparcialidad ha sido cuestionada: por ejemplo, estando pendiente ante la Corte un caso que involucraba al Vice-Presidente de los Estados Unidos, el juez Scalia se fue de caza con él, abriendo la puerta a toda clase de ataques. Lo interesante es que, estando Scalia convencido que no había lesión al principio de imparcialidad del tribunal -lo cual es, obviamente, muy discutible - entendió que debía articular una explicación a la ciudadanía de porqué tal era la situación y, así, Scalia elaboró un documento de 20 páginas en el que defendió su posición constitucional, negando de una parte el valor de la regulación legislativa, pero reafirmando por

Estados Unidos, quienes aspiran a un cargo en la Suprema Corte deben someterse a un examen riguroso sobre las cuestiones que han debido resolver o, incluso, respecto de posibles casos que podrían llegar hasta sus estrados. En Chile, tal debate no existe al momento de seleccionar a los miembros de la Corte Suprema o del Tribunal Constitucional. Esta diferencia, diré más adelante, tiene relevancia para analizar el caso que motiva este informe.

Corte Suprema de los Estados Unidos, Tumey v. Ohio 273 U.S. 510, 47 S.Ct. (1927)

Id.

Corte Suprema de los Estados Unidos, In re Murchinson 349 U.S. 136, 75 S.Ct., p. 625 (1955), citando Offutt v. United States, 348 U.S. 11 (1954). El destacado es mío.

United States Code, Titulo 28, § 455, (a). 
Jorge Contesse Singh

el mismo acto la gravitancia que para la integridad constitucional tiene esta materia.

$$
* * *
$$

Lo que demuestran los casos brevemente reseñados es que el estándar seguido por estas jurisdicciones constitucionales es uno que pone de lado del juzgador la carga de la prueba en todo caso en que "razonablemente" se pueda dudar acerca de su imparcialidad. O, como acaece en el caso español, aunque el estándar está fijado por el Tribunal Constitucional en términos diferentes, lo hace con igual propósito, cual es, custodiar que no exista siquiera margen de duda sobre la objetividad del tribunal. En efecto, de acuerdo con el TC hispano, "desde la óptica constitucional, para que en garantía de la imparcialidad un Juez pueda ser apartado del conocimiento de un asunto concreto es siempre preciso que existan dudas objetivamente justificadas". ${ }^{17}$

En cualquiera de las dos hipótesis, lo cierto es que ante el caso que deberá resolver el Tribunal Constitucional chileno, la actuación en calidad de coautores de los Ministros señores Bertelsen y Navarro arroja un manto de duda sobre su imparcialidad imposible de negar. Como ya he dicho, ellos articularon clara y explícitamente su opinión constitucional sobre la materia objeto del requerimiento, apoyando la pretensión de una de las partes litigantes, en un proceso judicial en el que se debatió la misma pregunta que ahora los demás Ministros conocen por primera vez. Lo anterior, como es obvio, no significa que los miembros de una corte constitucional no pueden tener opinión sobre los asuntos que son sometidos a su conocimiento. De hecho, difícilmente tal cosa podría suceder tratándose de juristas con una amplia trayectoria pública. De lo que se trata, como explico en la sección IV, es de ponderar de la mejor manera posible los dos ideales que pueden estar en tensión: de una parte, tal como he insistido a lo largo de estas páginas, el ideal de imparcialidad del tribunal y, de otra, la necesidad de dotar al Tribunal Constitucional de los mejores juristas constitucionales. Haciendo ese ejercicio de ponderación, no queda duda sobre la obligación de inhabilitarse que pesa sobre los Ministros señalados.

\section{Actuaciones previas del TC dan cuenta de un criterio no disputado ${ }^{18}$}

Al contrario de lo que podría pensarse, la pregunta que en estas páginas abordo ya ha sido encarada por el "nuevo" Tribunal Constitucional chileno, esto es, el Tribunal después de la reforma constitucional de 2005 que le otorgó mayores atribuciones (y, consecuentemente, mayores responsabilidades).

En a lo menos cuatro casos resueltos en los últimos dos años, Ministros del TC han entendido

Tribunal Constitucional de España, STC 26/2007, de 5 de febrero de 2007, parte II.3.

Agradezco a Macarena Sarras y Boris Lopicich por la recolección de datos para esta sección. 
Implicancias y Recusaciones: el caso del Tribunal Constitucional. Informe en derecho sobre la inhabilidad constitucional para conocer de un caso en el que se ha vertido opinión pública con anterioridad

que, precisamente por el hecho de haber emitido informes en derecho en calidad de especialistas en materias constitucionales, su imparcialidad puede ser legítimamente cuestionada y, por tanto, se han implicado.

Dos de estos casos se refieren a materias sobre regulación de servicios eléctricos ${ }^{19}$ y $\operatorname{los}$ otros dos se refieren a materias sobre regulación minera. ${ }^{20}$ En ellos, el presidente del TC, Ministro José Luis Cea Egaña, hace presente al Tribunal la circunstancia de haber emitido informes en derecho "en relación con la causa en que incide este requerimiento de inaplicabilidad", estimando "que se encuentra inhabilitado para conocer de este asunto". La respuesta del Tribunal es clara: "en atención a lo anteriormente expuesto, resuelve aceptar que presidente del Tribunal, Ministro José Luis Cea Egaña, no entre al conocimiento de esta causa...". ${ }^{21}$

En los otros dos casos -sobre regulación minera- nuevamente es el presidente del TC quien decide implicarse, aunque esta vez acompañado por el Ministro señor Hernán Vodanovic Schnake. La razón es la misma: la elaboración de sendos informes en derecho respecto de estas materias. ${ }^{22}$ Y la respuesta del Tribunal es uniforme: se acepta la inhabilidad del Presidente y del Señor Ministro.

La conclusión que de estas actuaciones es posible extraer no admite dobles lecturas: en orden a satisfacer el principio jurídico de la imparcialidad, materializado en la norma sobre implicancia contenida en el artículo 19 de la Ley $\mathrm{N}^{\mathbf{0}}$ 17.997, un Ministro del Tribunal Constitucional que se ha pronunciado técnicamente sobre estas materias en calidad de experto cae bajo la hipótesis de incidencia de la ley orgánica constitucional y debe, en consecuencia, inhabilitarse para conocer. De lo contrario - el propio Tribunal ha sugerido-, se dañaría la confianza depositada en el TC, lesionando de paso el orden constitucional que este órgano está llamado a defender.

En estos casos, el TC ha actuado en la dirección correcta, despejando cualquier posibilidad de crítica a su imparcialidad al momento de resolver un asunto constitucional. Debe señalarse, con todo, que el Tribunal no ha establecido con claridad cuál es el criterio que debe imperar en materia de implicancias y recusaciones, en particular, dado que se trata de un órgano cuyos miembros inevitable y necesariamente han manifestado opiniones técnicas de algún modo que legitime, antes que todo, el haber sido investidos como Ministros del TC. Los casos que caen

19 Tribunal Constitucional, sentencias recaídas en las causas Rol 505-2006 y Rol 506-2006, ambas de 6 de marzo de 2007.

20 Tribunal Constitucional, sentencias recaídas en las causas Rol 517-2006 y Rol 536-2006, ambas de 8 de mayo de 2007.

21 Tribunal Constitucional, causa Rol 506-2007, fj. 115.

22 Tribunal Constitucional, causa Rol 535-2007, fjs. 60 y 61. 
bajo la causal de implicancia obviamente son aquellos en los que los Ministros se han pronunciado no como Ministros, sino en una calidad distinta (por ejemplo, como académicos). Pues no tendría sentido recusar a un Ministro por las opiniones que, en sentencias anteriores pueda haber emitido. Si dichas opiniones no coinciden con lo que una parte litigante busca obtener, no es la recusación el camino a seguir, sino un esfuerzo por persuadir, dentro de las reglas del proceso, que el criterio que debe abrazar el juzgador es otro. Pero dicha cuestión no es materia de este escrito. Sí lo es, en cambio, decir algo sobre la manera como ha de abordarse la relación entre las opiniones expresadas en calidad de expertos $-\mathrm{y}$ que, como dije, legitiman en parte la investidura de los miembros del TC - y la obligación de cumplir con el principio de imparcialidad.

\section{El equilibrio entre imparcialidad y experticia}

A diferencia de los jueces que forman parte del Poder Judicial, al Tribunal Constitucional no llegan únicamente quienes han trabajado largamente en los tribunales, acumulando experiencia y desarrollando sus talentos, rindiendo examen ante sus superiores jerárquicos. $\mathrm{Al}$ TC llegan juristas que han destacado en la vida pública y académica por sus méritos a la hora de enfrentar preguntas constitucionales. Por lo anterior, y porque la naturaleza del TC es una que lo sitúa entre los órganos políticos y el Poder Judicial, no es sencillo aplicar directamente la regulación que para este último contempla la ley y la Constitución.

El carácter sui generis del Tribunal Constitucional queda demostrado en el mecanismo que se ha diseñado para nombrar a sus miembros, mezclando el carácter técnico con el ámbito político. Ello no debe extrañar, toda vez que se trata de la jurisdicción constitucional, la que resulta del enfrentamiento de ideologías políticas encauzadas por medio de la técnica legal.

De este modo, a la ciudadanía le interesa que sean los mejores juristas los que arriben al Tribunal Constitucional. Por ello es que se establece que debe tratarse de abogados, con a lo menos quince años de experiencia, que se hayan destacado en la actividad profesional, universitaria o pública. ${ }^{23}$ Y la manera que los órganos políticos, a cuyo cargo está el designar a los miembros del TC, tienen de asegurarse que los candidatos cumplan con los requisitos establecidos por la Constitución es, entre otras cosas, seleccionar a personas que han influido y participado de la vida constitucional chilena. Una de las formas de hacer ello es por medio de publicaciones científicas.

Pero, además, los órganos políticos deben escrutar a los candidatos que pretenden custodiar el orden constitucional, por lo cual -en teoría— deben someterlos a examen sobre su pensamiento constitucional. ${ }^{24}$ No se trata de evaluar las ideologías o afiliaciones políticas que los futuros

23 Constitución Política, artículo 92, inciso $2^{\circ}$.

24 Digo "en teoría" porque hasta ahora la comparecencia al Senado de los candidatos al TC ha estado lejos de 
Implicancias y Recusaciones: el caso del Tribunal Constitucional. Informe en derecho sobre la inhabilidad constitucional para conocer de un caso en el que se ha vertido opinión pública con anterioridad

miembros de un TC tengan, pero sí de exigir que ellas sean traducidas en apreciaciones acerca de la interpretación constitucional.

¿Cómo es posible, entonces, conciliar la exigencia de escrutinio del pensamiento constitucional de los candidatos con la independencia que deben tener como jueces constitucionales? O, dicho de otra manera, ¿cómo puede un destacado abogado ser candidato al TC y no quedar inhabilitado a futuro? La respuesta, creo, es posible articularla teniendo presente que estamos en presencia de dos principios jurídicos que entran en tensión. La solución a ello, consecuentemente, radica en la mejor ponderación que el legislador o el juez, en particular, pueda hacer de estos principios. A continuación ofrezco algunos pensamientos al respecto y una respuesta para este caso en particular.

Cuando dos principios jurídicos entran en tensión, como suele ocurrir en la teoría y práctica constitucional, la manera de conciliarlos radica en aquello que la doctrina denomina "ponderación de bienes jurídicos". En la formulación del jurista alemán Robert Alexy, la ponderación de principios jurídicos da lugar a una "ley de precedencia condicionada", en cuya virtud un principio jurídico tendrá primacía - "precedencia"- sobre otro según cuáles sean las condiciones particulares del caso en particular que reclama la intervención de dichos principios (de allí que la precedencia sea "condicionada"). ${ }^{25}$ Así, por ejemplo, en un caso en que por una parte se alegue una invasión a la intimidad o privacidad y, de otra, se reclame el derecho a informar, la respuesta al conflicto vendrá dada por las circunstancias particulares del caso en el que se reclaman dicho derechos fundamentales. Así, el juzgador, para resolver, deberá preguntarse acaso se trata de un funcionario público o una persona privada quien alega la invasión a su esfera privada; acaso la información de que se trata es de interés público o no; si es que fue obtenida por medios lícitos o mediante engaño, entre otras variables. Como es obvio, esta técnica de interpretación constitucional, presente en países como Alemania, Canadá y, aunque con otra nomenclatura, Estados Unidos, excluye toda posibilidad de un orden jerárquico en materia de derechos fundamentales. Siguiendo con el ejemplo, no es que la libertad de expresión (o el derecho a la privacidad) sea "a todo evento" más importante que el otro derecho en tensión, sino que en un caso determinado, bajo tales y cuales condiciones, uno de los dos precederá en su aplicación al otro. Por lo mismo, en un caso diferente, en el que las condiciones

significar un momento de reflexión acerca de las formas de interpretar la Constitución. Más bien, pareciera que los parlamentarios se contentan con verificar que los antecedentes curriculares de los futuros miembros no merezcan reparo y, en acuerdos adoptados previa o paralelamente, se procede a aprobar la designación de uno o más miembros. La comparación que unas páginas más atrás hacia con la manera como se realiza la selección de jueces de la Suprema Corte en los Estados Unidos cobra aquí sentido: mientras allá senadores, candidatos e incluso ciudadanos interesados se trenzan en un fructífero debate constitucional, en nuestro país ello parece suponer un ataque a la independencia de los jueces. Por cierto, esta crítica debe dirigirse a los órganos políticos, y no al Tribunal Constitucional.

Alexy, op. cit. 
fácticas y jurídicas varíen, la respuesta bien puede variar, sin que ello implique desviarse del orden constitucional. En ningún caso ello implica que un derecho fundamental "no se aplique"; sino simplemente ha de ceder ante la mayor fuerza relativa del otro principio.

En el caso que anima estas páginas también es posible realizar un ejercicio de ponderación entre dos bienes jurídicos de igual importancia. Como ya he señalado, por una parte, el principio de imparcialidad del tribunal se sitúa como mandato de optimización al que toda labor jurisdiccional debe tender y, por otra, puede decirse que el contar con los mejores juristas aparece como otro mandato de optimización que, en este caso, colisiona con la imparcialidad. La colisión, desde luego, no es evidente: se produce toda vez que la mayor o menor calidad profesional de quienes componen el TC viene dada, inter alia, por las publicaciones o intervenciones profesionales que hayan tenido a lo largo de su trayectoria. En otras palabras, por sí solo, el que dos Ministros hayan elaborado un informe en derecho sobre materias constitucionales no es un atentado a la imparcialidad del juzgador; puede serlo una vez que al tribunal le corresponde pronunciarse sobre dichas materias. Y la manera de determinar qué debe primar, si el principio de imparcialidad que ordena a los magistrados excluirse del conocimiento o su, digamos, derecho a intervenir en la vida constitucional del país sin que de ello se sigan consecuencias como la implicancia, es atendiendo a las circunstancias particulares del caso. Solo después de realizado este ejercicio estaremos en condiciones de saber qué tiene precedencia en el caso particular.

Pues bien, al examinar las condiciones fácticas y jurídicas del caso que analizamos -el requerimiento presentado por 32 diputados en contra del Decreto Supremo 48/2007 del Ministerio de Salud - resulta evidente que la lesión al principio de imparcialidad del tribunal es más intensa que el ejercicio del "derecho" de los Ministros, como académicos, a pronunciarse públicamente sobre un tema constitucional. ${ }^{26}$ Veamos.

- Los Ministros señores Bertelsen y Navarro participaron de un informe en derecho que se refiere directa y explícitamente a la materia sobre la que hoy, de no inhabilitarse, tendrán que conocer. No se trata, como ocurrió en el caso del TC español examinado más atrás, de un estudio que pudo o no haber servido en un caso similar.

- La materia objeto del informe -y del requerimiento-, es exactamente la misma que motivó la intervención de los Ministros en el juicio seguido ante la justicia ordinaria.

- Se trata de un caso de alto interés público. Lo anterior ordena el mayor celo por parte de los miembros del Tribunal Constitucional.

- En casos anteriores, miembros del TC han decidido marginarse de conocer de casos sobre asuntos en los que han vertido su opinión profesional. Habiendo aquí la misma razón, no

26 La publicidad de su pronunciamiento no está dada necesariamente por dar a conocer sus ideas por medios masivos; basta, para estos efectos, que dicha opinión sea promovida en sede jurisdiccional toda vez que los actos procesales son, por regla general, públicos. 
Implicancias y Recusaciones: el caso del Tribunal Constitucional. Informe en derecho sobre la inhabilidad constitucional para conocer de un caso en el que se ha vertido opinión pública con anterioridad

se divisa motivo por el que no deba aplicarse la misma disposición.

- Por medio de sus abogados integrantes, el TC tiene cómo suplir a los Ministros implicados (de hecho, es lo que ha ocurrido en los casos reseñados en la sección III).

- Adoptar una decisión en este sentido no significa que para todos los casos a futuro la respuesta deba ser la misma.

\section{Conclusión}

Por las razones expuestas anteriormente, mi opinión es que en la causa Rol No $740-2007$ los Ministros señores Raúl Bertelsen Repetto y Enrique Navarro Beltrán se encuentran en la causal de implicancia contenida en el artículo 19 de la ley orgánica del Tribunal Constitucional $\mathrm{y}$, por lo tanto, deben inhabilitarse de conocer.

Las normas actualmente vigentes sobre el Tribunal Constitucional, en conjunto con la práctica constitucional de otros países, las propias actuaciones previas de otros miembros del TC y la necesidad de satisfacer en la mayor medida posible el principio de imparcialidad del tribunal inequívocamente así lo ordenan.

De no marginarse de conocer y resolver un requerimiento respecto del cual la ciudadanía conoce a cabalidad cuál es la posición jurídica de los señores Ministros, el mensaje que desde el órgano encargado de custodiar la Constitución se enviaría es que no importa que la justicia abra los ojos y, en vez de pesar los argumentos de las partes, los mire desvergonzadamente. Para quienes estamos comprometidos con la integridad de las instituciones y, en particular, con el buen desempeño de la justicia constitucional lo anterior debe resistirse. El Tribunal Constitucional está en condiciones de articular una regla, aun provisoria, sobre cómo abordar las situaciones en las que pueda presentarse una duda sobre la imparcialidad de sus miembros. Así, no correspondería dejar de hacer lo anterior en atención a que se discute en el Congreso Nacional la ley que regulará la labor del TC. La historia constitucional da cuenta de casos en que las cortes, preocupadas más por la justicia de sus actos que de las formas jurídicas, ha hecho prevalecer la primera. Hacer ello, en efecto, serviría a reforzar la determinante labor que en nuestro país está cumpliendo el garante de la Constitución. 